\title{
Local confidential inquiry into avoidable factors in deaths from stroke and hypertensive disease
}

\author{
J N Payne, P C Milner, C Saul, I R Bowns, D R Hannay, L E Ramsay
}

Department of Public Health, Rotherham Health Authority, Rotherham JN Payne, senior registrar P C Milner, director C Saul, research assistant

Department of Public Health, Barnsley Health Authority, Barnsley

I R Bowns, director

Departments of General Practice and Pharmacology and Therapeutics,

Sheffield University Medical School, Sheffield D R Hannay, head of general practice

LE Ramsay, consultant physician

Correspondence to: Dr Payne, Department of Public Health, Nether Edge Hospital, Sheffield S11 9EL.

$B M f 1993 ; 307: 1027-30$

\section{Abstract}

Objective-To audit avoidable deaths from stroke and hypertensive disease.

Design-Details of care before death were obtained from general practitioners and other doctors, anonymised, and assessed by two experts against agreed minimum standards of good practice for detecting and managing hypertension.

Setting-Health authority with population of 250000.

Subjects-All patients under 75 years who died of stroke, hypertensive disease, or hypertension related causes during November 1990 to October 1991.

Main outcome measures-Presence of important avoidable factors and departures from minimum standards of good practice.

Results-Adequate information was obtained for 88\% (123/139) of eligible cases. Agreement between the assessors was mostly satisfactory. $29 \%(36 / 123$, $95 \%$ confidence interval $21 \%$ to $37 \%$ ) of all cases and $44 \%(36 / 81,34 \%$ to $55 \%)$ of those with definite hypertension had avoidable factors that may have contributed to death. These were most commonly failures of follow up and continuing smoking. Assessment against standards of minimum good practice showed that care was inadequate but not necessarily deemed to have contributed to death, in a large proportion of patients with definite hypertension. Common shortcomings were inadequate follow up, clinical investigation, and recording of smoking and other relevant risk behaviours.

Conclusions-This method of audit can identify shortcomings in care of patients dying of hypertension related disease.

\section{Introduction}

Cerebrovascular disease accounts for around $12 \%$ of all deaths and $5 \%$ of deaths in people under the age of 65 in England and Wales. The government recently set a target of a $40 \%$ reduction in death from stroke in people under 75 in England by $2000 .{ }^{1}$ Hypertensive and cerebrovascular disease is one of the most common causes of death covered by avoidable death indicators. ${ }^{2}$

Confidential inquiry into deaths from specific causes has been shown to improve care. The maternal death inquiry began in the early 1950 s and is believed to have substantially improved standards of obstetric care. ${ }^{3}$ Similarly the confidential enquiry into perioperative deaths (CEPOD) has had a considerable impact on the organisation of surgical services. ${ }^{4}$ We describe a method of locally based confidential inquiry into deaths from cerebrovascular and hypertensive disease. The audit concentrated particularly on the adequacy of detection, treatment, and control of hypertension, which others have described as often unsatisfactory. ${ }^{56}$
We present the main results of an audit in an average sized health district.

\section{Subjects and methods}

After obtaining approval from the ethics committee we sent letters to all general practitioners and hospital consultants in the district explaining the study and encouraging them to participate. We also publicised the study at meetings of local doctors.

We studied all deaths in patients under 75 years certified as due to hypertensive disease or cerebrovascular disease ${ }^{7}$ and deaths due to ischaemic heart disease or other conditions related to hypertension in which hypertension was given as a significant condition in part II of the death certificate. Patients were entered into the study from 1 November 1990 to 31 October 1991. All were resident in the district and registered with a general practitioner responsible to the conterminous family health services authority.

\section{COLLECTION OF DATA}

Information on the pattern of care received by patients was obtained by a non-medical research assistant (CS). She visited the practices and completed a specially designed and piloted questionnaire by interviewing the general practitioners, who used both case notes and their recollections of the patients to provide the answers. If there had been shared care for hypertension or related complications the hospital consultant was also interviewed in the same way. Relevant information obtained during other unrelated hospital care up to two years before death-for example blood pressure measurements-was extracted from hospital case notes. When general practitioners declined to be interviewed but made their case notes available JNP extracted the clinical data from these. In one case only the hospital consultant provided information. The certified cause of death was verified in all cases.

No named data relating to patients or doctors were collected on the questionnaires, and all possible links with identifiable data were removed after the interviews. The data on each patient were sent to two assessors (LER, DRH), who reviewed them separately. The assessors were from outside the district; LER has a special interest and considerable experience in hypertension and DRH is a senior academic general practitioner. From the results of randomised clinical trials, they produced a written protocol of minimum standards for managing hypertension.

\section{METHOD OF ASSESSMENT}

The assessors completed a questionnaire for each case. If they disagreed on whether the patient was hypertensive or whether there were important avoidable factors they were asked to review the case and reach a consensus decision. 
The assessment consisted of two independent parts. The first part determined whether any failure could have contributed to a patient's death. Such failure could be part of medical care-for example, failure to treat hypertension - or be a failure of the patient - for example, continuing to smoke. The assessors agreed that it was appropriate to make a judgment on the presence or absence of avoidable factors only in those patients who were definitely hypertensive.

Initially, a low level of agreement was reached on presence of avoidable factors as the assessors were working to different criteria. After discussion it was agreed that the criteria for defining hypertension would be patient receiving antihypertensive drugs; diastolic blood pressure greater than $90 \mathrm{~mm} \mathrm{Hg}$ recorded before the terminal illness that was not documented as returning to normal; or hypertension during the terminal illness that was not explained by the terminal illness itself. The following main criteria were applied when deciding if important avoidable factors were present: uncontrolled hypertension when death was due to stroke, heart failure, or renal failure; failure to stop smoking when death was due to ischaemic heart disease (but not stroke); or failure to treat complications of hypertension. After these criteria were applied complete agreement was reached on whether important avoidable factors were present.

The second part of the assessment was to examine whether care met the predetermined minimum standards for mannaging hypertension. Failure to meet one standard was not necessarily considered to have contributed greatly to a patient's death.

Interassessor agreement was measured by Cohen's $\kappa$ statistic, which takes account of chance agreement. ${ }^{8}$ A value of +1.0 indicates complete agreement, 0.0 no agreement, and -1.0 complete disagreement. Agreement was assessed for all cases. Intra-assessor agreement was examined by resubmitting a random sample of 10 cases that had been assessed around six months earlier.

\section{Results}

Doctors caring for the patients before death agreed to be interviewed in 111 of 139 cases. In a further 12 they agreed for the case notes to be used. The proportion of cases in which the general practitioners participated was $90 \%$ half way through the study and $80 \%$ at the end. Six general practitioners who had agreed to earlier interviews declined to be interviewed about subsequent cases. The interview with the general practitioner was the sole source of information for 61 cases and additional information from hospital was available in 49 .

During the study there were 115 general practitioners registered with the family health services authority. The mean number of cases per general practitioner was $1 \cdot 2$, with 47 general practitioners having no patients eligible for entry and 15 having more than two. The maximum number of patients from one general practitioner was six. This is not notably different from that expected from a Poisson distribution and the high numbers associated with some general practitioners probably occurred by chance. The median time for each interview with doctors was 15 (range 8-24) minutes.

Table I shows the results of interassessor and intraassessor agreement. The intra-assessor agreement is low because the criteria for defining avoidable factors were determined in between the two assessments. The test is therefore an assessment of the agreement with the criteria rather than of variability with time.

Of the 123 deaths that were assessed, 84 were due to stroke and 15 to hypertensive disease; in 24 hypertension was given as an important condition on the

\section{Examples from three cases of important avoidable factors}

- Cerebral haemorrhage in a patient aged 45-49 years with raised blood pressure $(160 / 115 \mathrm{~mm} \mathrm{Hg})$ detected eight years before death but not treated or followed up

- Myocardial infarction in a hypertensive patient aged 55-59 years who did not stop smoking (40 cigarettes/day) despite advice. The patient was obese and defaulted from referral to dietician

- Stroke in a patient aged 65-69 years with unstable angina and a previous transient ischaemic attack. Detected hypertension was not followed up for two years and was inadequately controlled for four years before death. Aspirin was not prescribed

death certificate. Patients whose deaths were assessed were compared by sex, age, and cause of death with those who were not assessed. No significant difference was found by $\chi^{2}$ tests.

Both assessors agreed that the patient was definitely hypertensive in 81 cases. The proportions judged definitely hypertensive were similar in those aged under $65(69 \%, 31 / 45)$ and those aged $65-74(64 \%$, $50 / 78)$. Of the patients who died of stroke, $56 \%(47 / 84)$ were assessed as definitely hypertensive. For five of the 39 patients with hypertension on part II of the death certificate the assessors could not confirm hypertension.

\section{AVOIDABLE FACTORS}

The assessors agreed that in 36 patients with definite hypertension there were avoidable factors that probably contributed to death. This represents $29 \%$ (36/123, $95 \%$ confidence interval $21 \%$ to $37 \%$ ) of all cases entered into the study and $44 \%(36 / 81,34 \%$ to $55 \%)$ of those who were assessed as definitely hypertensive.

A smaller proportion of patients with stroke had important avoidable factors $(26 \%, 22 / 84)$ than of those whose death was due to other causes $(36 \%, 14 / 39)$. Of those meeting the exact age and diagnostic criteria for avoidable death indicators for hypertensive or cerebrovascular disease, ${ }^{2} 27 \%$ (10/37) were considered to have important avoidable factors. If the assessors considered that important avoidable factors were present they were asked to specify what they were. The box gives some examples.

The avoidable factors from all 36 cases were divided into the eight categories (table II). The largest category was failure to follow up and treat hypertension once diagnosed.

\section{DEPARTURE FROM MINIMUM STANDARDS}

Departures from minimum standards of care were analysed irrespective of whether the assessors considered that they had probably contributed to death. Table III shows the number of patients for whom assessors agreed minimum standards of care were not met.

TABLE I-Interassessor and intra-assessor agreement on questionnaires about cause of death ( $\kappa$ values)

\begin{tabular}{llll}
\hline & & \multicolumn{2}{c}{ Intra-assessor } \\
\cline { 3 - 4 } Question & Interassessor & Assessor 1 & Assessor 2 \\
\hline $\begin{array}{l}\text { Was the patient hypertensive? } \\
\begin{array}{l}\text { Was there a failure of opportunistic } \\
\text { case finding? }\end{array}\end{array}$ & $1(0.8)^{\star}$ & 0.84 & 0.55 \\
$\begin{array}{l}\text { Was follow up adequate? } \\
\text { If treatment was not started, should } \\
\text { it have been? }\end{array}$ & 0.9 & 1.0 & 1.0 \\
$\begin{array}{c}\text { If treatable complictions occurred } \\
\text { were they diagnosed and treated }\end{array}$ & 0.9 & 0.86 & 0.84 \\
$\begin{array}{c}\text { appropriately? } \\
\text { Overall assessment of avoidable } \\
\text { factors }\end{array}$ & 0.7 & 0.86 & 0.72 \\
\hline
\end{tabular}

$\star$ Value achieved before criteria were agreed is given in parentheses. 
TABLE II-Numbers of hypertensive patients with avoidable factors contributing to death identified by assessors

\begin{tabular}{lc}
\hline & $\begin{array}{c}\text { No of patients } \\
(\mathrm{n}=36)\end{array}$ \\
\hline $\begin{array}{l}\text { Failure of the health service to: } \\
\text { Detect hypertension }\end{array}$ & 1 \\
$\quad$ Follow up and treat hypertension once diagnosed & 25 \\
Ensure that patients were recalled if they missed follow up & 3 \\
$\quad$ appointments & 3 \\
$\quad \begin{array}{l}\text { Diagnose and treat complications of hypertension } \\
\text { Failure of the patient to: }\end{array}$ & 3 \\
Take drugs or agree to attend for follow up & 13 \\
Stop smoking & 6 \\
Lose weight & 8 \\
\hline Reduce alcohol consumption & \\
\hline
\end{tabular}

TABLE III-Number of cases in which both assessors agreed minimum standards of care were not met among 81 hypertensive patients

\begin{tabular}{lc}
\hline & Number of cases \\
\hline Opportunistic case finding & 2 \\
Follow up & 56 \\
Starting treatment & 5 \\
Urine analysis & 28 \\
Blood urea and electrolyte measurement & 33 \\
Diagnosis and treatment of complications & 4 \\
Referral & 2 \\
Recording of smoking history & 21 \\
Recording of alcohol consumption & 49 \\
Recording of weight & 28 \\
\hline
\end{tabular}

In two of the 81 definitely hypertensive patients there was inadequate opportunistic case finding; in these cases blood pressure had not been measured in the five years before death despite contact with medical services. Because of the way the cases were ascertained opportunistic case finding is unlikely to be deficient in this group. By contrast, opportunistic measurement of blood pressure was deficient in $24 \%(10 / 42)$ of the patients who did not have definite hypertension.

Antihypertensive treatment was not started in five patients and in 56 follow up and control were inadequate. In 28 patients urine analysis was not done at the time of diagnosis, and in 33 blood urea and electrolyte concentrations were not measured. Only four patients did not have complications diagnosed or treated. All four were not given aspirin for transient ischaemic attacks. Twenty nine patients had good indications for referral because of failure to control hypertension or because of complications but only two patients were not referred.

Evidence was recorded of advice on smoking in $75 \%$ (27/36) of patients known to be smokers, on reduction of alcohol intake in 44\% (4/9) of those known to be heavy drinkers, and on weight reduction in $81 \%$ (30/37) of those known to be overweight.

\section{Discussion}

Most doctors agreed to take part in the audit, at least initially, and even by the end of the study the participation rate was $80 \%$. It was unfortunate that $8 \%$ of eligible general practitioners had four or more deaths among their patients because several requests for interviews might lead to reluctance to participate.

The two questionnaire methodology, based on that used by the first confidential enquiry into perioperative deaths, ${ }^{4}$ allowed a high level of confidentiality to be maintained. Although there was disagreement between the assessors, after criteria had been agreed the assessors were easily able to reach a consensus.

\section{ASSESSMENTS}

Two methods of analysing the results were used. The first was based on the assessors' judgment whether avoidable factors were present that may have contributed to death. Such factors were found in $29 \%$ of cases.

There are several reasons why the audit may have underestimated the presence of important avoidable factors. Firstly, the care received was compared with minimum rather than the optimum standards for managing hypertension. Secondly, we did not examine failures to diagnose and certify hypertension in cases of ischaemic heart disease when hypertension was not mentioned on the death certificate. Thirdly, systolic blood pressure was ignored, although recent evidence points to its importance. Fourthly, although we assumed that all patients who died of stroke and hypertensive disease could have benefited from treatment, no such assumption was made in patients dying of ischaemic heart disease because the evidence has been uncertain until recently. ${ }^{9-11}$ Fifthly, smoking and high alcohol consumption were regarded as insufficient to have contributed to death from stroke in normotensive patients, although there is epidemiological evidence that this may be the case. ${ }^{11-14}$ Evidence of the benefit of stopping smoking in preventing ischaemic heart disease is much clearer, and this was reflected in the assessors' decisions. ${ }^{15}$ Finally, the data available and their accuracy are more likely to underestimate important avoidable factors.

Although minimum standards for managing hypertension were agreed as a basis to assess important avoidable factors, to some extent the assessments were subjective. In the second method of analysing the results individual aspects of management were considered, irrespective of whether the assessors considered that they contributed to death.

The biggest problem was in follow up, which was considered inadequate in over two thirds of hypertensive patients. An audit of case notes in London general practices found that $69 \%$ of patients with hypertension had not had their blood pressure measured for more than a year. ${ }^{5}$ A similar proportion $(56 \%)$ was found in a Scottish study. ${ }^{16} \mathrm{~A}$ larger study of three practices that used protocols for health checks run by nurses found improved follow up of hypertensive patients-over $70 \%$ were seen annually over three years. ${ }^{17}$ Other studies have reported inadequate control of blood pressure in $25-59 \%$ of hypertensive patients. $^{56}$ 17-19

We found lower proportions of cases in which there were deficiencies in opportunistic case finding or in starting treatment than most practice based audits. ${ }^{5619-21}$ As discussed earlier, however, this may be partly because of the way our non-stroke cases were ascertained.

The assessors considered that investigations in hypertensive patients should include urea and electrolyte measurement and urine analysis. ${ }^{22}$ This was done in only about two thirds of patients, which is a larger proportion than the $26 \%$ and $30 \%$ in two earlier reports ${ }^{517}$ but lower than the $74 \%$ reported in a single practice study. ${ }^{23}$

\section{Clinical implications}

- Confidential inquiries are an established and successful method of auditing care

- This study showed that a local confidential inquiry with high participation can be set up and used to investigate avoidable factors in deaths from stroke and hypertensive disease

- Avoidable factors that may have contributed to such deaths were identified in $29 \%$ of cases; of these, inadequate follow up and failure to stop smoking were the most common

- Comparison of care received against minimum standards of good practice revealed other shortcomings such as in clinical investigation and in recording of risk behaviours 
Encouraging patients to reduce or stop smoking is an important aspect of care. Smoking habits were recorded in $76 \%$ of patients, which compares well with the $44 \%$ found in an audit in 12 Oxfordshire practices in $1986 .{ }^{24}$ Weight was recorded in $61 \%$ of cases compared with $31 \%$ in the Oxfordshire audit. ${ }^{24}$ Although heavy alcohol consumption may be as important a risk factor for stroke as smoking, only $40 \%$ of cases had a history of alcohol use recorded and only $44 \%$ of heavy drinkers had recorded evidence of advice on reducing consumption.

We thank Drs B Hillman and B K Mondal (members of the local steering group); the Department of Health for funding; Professor Richard Alderslade, director of public health, Trent Regional Health Authority; the general practitioners and hospital doctors who took part; and Mrs Greta Pearman.

\footnotetext{
1 Department of Health. The health of the nation. London: HMSO, 1992.

(Cm 1523.)
2 Rutstein DD, Brenberg W, Chalmers TC, Child CG III, Fishman AP, Perrin EB. Measuring the quality of medical care: a clinical method. $N$ Engl $₹$ Med 1976;294:582-8.

3 Department of Health, Welsh Office, Scottish Home and Health Department Department of Health and Social Security, Northern Ireland. Report on confidential enquiries into maternal deaths in the United Kingdom 1985-1987. London: HMSO, 1991.

4 Buck N, Devlin HB, Lunn JN. The report of the confidential enquiry into perioperative deaths. London: Nuffield Provincial Hospitals Trust, 1987.

$5 \mathrm{Kurji} \mathrm{KH}, \mathrm{Haines} \mathrm{AO}$. Detection and management of hypertension in general practices in north west London. BMF 1984;288:903-6.

6 Smith WC, Lee AJ, Crombie IK, Tunstall-Pedoe H. Control of blood pressure in Scotland: the rule of halves. $B M$ T 1990;300:981-3.
}

7 World Health Organisation. Manual of the international statistical classification of disease: inquiries and causes of death (ninth revision). Geneva: WHO, 1977 8 Fleiss JL. Statistical methods for rates and proportions. New York: Wiley, 1981.

9 Medical Research Council Working Party. MRC trial of treatment of mild hypertension: principal results. $B M \Im$ 1985;291:97-104.

10 Collins R, Peto R, MacMahon S, Hebert P, Fiebach NH, Eberlein KA, et al. Blood pressure, stroke, and coronary heart disease. II. Short term reductions in blood pressure: overview of randomised drug trials in their epidemiological context. Lancet 1990;335:827-38.

11 Medical Research Council Working Party. Medical Research Council trial of treatment of hypertension in older adults: preliminary results. $B M F$ 1992;304:405-12.

12 Gordon T, Kannel WB. Predisposition to atherosclerosis in the head, heart, and legs. The Framingham study. JAMA 1972;221:661-6.

13 Shaper AG, Phillips AN, Pocock SJ, Walker M, Macfarlane PW. Risk factors for stroke in middle aged British men. BMF 1991;302:1111-5.

14 Gill JS, Zezulka AV, Shipley MJ, Gill SK, Beevers DG. Stroke and alcohol consumption. N Engl f Med 1986;315:1041-6.

15 Doll R, Hill AB. Mortality in relation to smoking: ten years' observations of British doctors. $B M \mp 1964 ; \mathrm{i}: 1399-410,1460-7$.

16 Ritchie LD, Currie AM. Blood pressure recording by general practitioners in north-east Scotland. BMF 1983;286:107-9.

17 Mant D, McKinlay C, Fuller A, Randall T, Fullard EM, Muir J. Three year follow-up of patients with raised blood pressure identified at health checks in general practice. $B M F$ 1989;298:1360-2

18 Wilson JB. An audit of hypertension in a rural practice. Practitioner 1978;220:689-92.

19 Chapman A, Ridout S. Hypertensive care and the small practice. Practitioner 1989;233:1018-22.

20 Michael G. Quality of care in managing hypertension by case finding in northwest London. BMF 1984;288:906-8.
not in

21 Hall JA. Audit of screening for hypertension in general practice. $f R$ Coll $G e$ Pract 1985;35:243.

22 Strasser $T$. Guidelines for the treatment of mild hypertension: memorandum from a WHO/ISH meeting. 7 Hypertension 1986;4:383-6.

23 Taffinder AP, Taffinder GA. An audit of hypertension in general practice. Practitioner 1984;228:595-8.

24 Stern D. Management of hypertension in twelve Oxfordshire general practices. f $R$ Coll Gen Pract 1986;36:549-51.

(Accepted 24 August 1993)

\section{Second malignant neoplasms after cancer in childhood or adolescence}

Jørgen H Olsen, Stanislaw Garwicz, Henrik Hertz, Gudmundur Jonmundsson, Frøydis Langmark, Marjatta Lanning, Sverre O Lie, Peter Johan Moe, Torgil Møller, Risto Sankila, Hrafn Tulinius for the Nordic Society of Paediatric Haematology and Oncology Association of the Nordic Cancer Registries

\section{Abstract}

Objective-To assess the relative risk of developing a second malignant neoplasm in people with a diagnosis of cancer in childhood and adolescence.

Design-Register based follow up study.

Setting-Populations of Nordic countries.

Subjects-30 880 people under the age of 20 with a first malignant neoplasm diagnosed during the period 1943-87.

Main outcome measures-Relative and attributable risks of second malignant neoplasms by type of first cancer, age at first diagnosis, calendar period, sex, and country. Expected figures were based on the appropriate national incidence rates for cancer.

Results -247 cases of second malignant neoplasms were observed in 238 patients, yielding a relative risk for cancer of 3.6 (95\% confidence interval $3 \cdot 1$ to $4 \cdot 1)$. The risk changed significantly from 2.6 in people first diagnosed during the 1940 s and 1950 s to 6.9 among cohort members included in the late 1970s and 1980s. Increases were observed for most types of cancer. Highest levels of the relative risk were seen during the 10 years immediately after first malignant diagnosis. The incidence of second malignant neoplasms attributable to the first cancer and associated treatments, however, showed a consistent rise throughout the 45 years of follow up.

Conclusion-The estimated risks for a second malignant neoplasm were significantly lower than those found in most large hospital based studies but compatible with the results from a similar population based study in the United Kingdom. Extent of risk and cancer pattern were similar among the Nordic countries and are believed to be representative for a large part of the European population.

\section{Introduction}

Cancer occurs in children and adolescents aged under 20 in the five Nordic countries (Denmark, Finland, Iceland, Norway, and Sweden) at an annual rate of 136 cases per 1 million. The rates have, in general, been unchanged since the inception of the nationwide cancer registries in all of the countries during the 1940 s and 1950 s. Survival rates from childhood cancer have improved substantially over the past two to three decades, which implies that a growing number of adults have been exposed to high doses of cytostatic drugs or radiation, or both, during childhood.

The risk for a second malignant neoplasm after cancer in childhood or adolescence seems to be high relative to that in the general population ${ }^{1-10}$ and also in comparison to the relative risk for second tumours observed after a first tumour diagnosed late in life. ${ }^{11}$ Owing to the rarity of cancer in young people, however, the risk estimates for a second malignant neoplasm among such individuals generally have wide confidence intervals.

In this collaborative study from the Nordic countries, the incidence of second malignant neoplasm was assessed in large, population based cohorts of survivors of a first malignant neoplasm at the age of 0-19 years and compared with the appropriate rates of cancer in 